\title{
Chapter 7 \\ Radioactive Nuclides in Vegetables and Soil Resulting from Low-Level Radioactive Fallout After the Fukushima Daiichi Nuclear Power Plant Accident: Case Studies in Tokyo and Fukushima
}

\author{
Seiichi Oshita
}

\begin{abstract}
Vegetables and field soils about 60 and $230 \mathrm{~km}$ away from the Fukushima Daiichi nuclear power plant were examined for ${ }^{134} \mathrm{Cs}$ and ${ }^{137} \mathrm{Cs}$ radioactivity. The total ${ }^{134} \mathrm{Cs}$ and ${ }^{137} \mathrm{Cs}$ transferred was $<7 \mathrm{~Bq} / \mathrm{kg}$ wet weight in potato tubers grown in fields where the total ${ }^{134} \mathrm{Cs}$ and ${ }^{137} \mathrm{Cs}$ concentration in the soil was $\leq 1,235 \mathrm{~Bq} / \mathrm{kg}$ dry weight. For the edible parts of lettuce and cabbage, the total ${ }^{134} \mathrm{Cs}$ and ${ }^{137} \mathrm{Cs}$ concentrations were lower than the detection limit. In this case, the maximum value in soil was $651.2 \mathrm{~Bq} / \mathrm{kg}$ dry weight.
\end{abstract}

Keywords Cabbage • Cesium-134 • Cesium-137 • Lettuce • Low level

- Potassium-40 • Potato • Soil

\subsection{Introduction}

The nuclear power plant accident that occurred in Fukushima Prefecture in March 2011, caused a wide spread of radioactive nuclides over various parts of Japan. This raised the immediate concern that agricultural products might become directly contaminated by radioactive nuclide fallout. Therefore, an investigation of the contamination of vegetables by radiocesium $\left({ }^{134} \mathrm{Cs}\right.$ and $\left.{ }^{137} \mathrm{Cs}\right)$ was initiated about 2 months after the accident (Oshita et al. 2011, 2013).

For this investigation, vegetable samples were collected from the fields at the Institute for Sustainable Agro-ecosystem Services, Graduate School of Agricultural and Life Sciences, The University of Tokyo, located in Nishitokyo City, Tokyo. Samples were also collected from fields near a mountain village in Fukushima Prefecture.

\footnotetext{
S. Oshita $(\square)$

Department of Biological and Environmental Engineering, Graduate School of Agricultural and Life Sciences, The University of Tokyo, 1-1-1, Yayoi, Bunkyo-ku, Tokyo 113-8657, Japan e-mail: aoshita@mail.ecc.u-tokyo.ac.jp
} 
Another possible problem, which could have developed over time in addition to direct contamination, was the transfer of radioactive nuclides through root absorption (indirect contamination). Therefore, the transfer of radioactive nuclides from the soil was studied by intentionally spreading high-concentration radioactive nuclides onto culture media. Previous studies examined rice plants (Tensho et al. 1959; Yonezawa and Mitsui 1965; Tsumura et al. 1984), grapes (Zehnder et al. 1995), mushrooms (Ban-nai et al. 1994) and field crops (Uchida et al. 1987; Ban-nai et al. 1995; Ban-nai and Muramatsu 2002). Another study assessed the effects of environmental radioactivity on foodstuffs (Schwaiger et al. 2004). To examine radionuclide transfer coefficients, ${ }^{137} \mathrm{Cs}$ at an extremely high concentration was used in many cases such as the paper by (Ban-nai et al. 1995) [490 kBq/pot (about 163 $\mathrm{kBq} / \mathrm{kg}$, as the one pot was filled with $3.0 \mathrm{~kg}$ of the soil)] and that by (Broadley and Willey 1997).

In the results reported here, the amounts of radiocesium $\left({ }^{134} \mathrm{Cs}+{ }^{137} \mathrm{Cs}\right)$ transferred from the field soil to vegetables at a low concentration in the soil of $\leq 1,235 \mathrm{~Bq} / \mathrm{kg}$ dry weight were measured in order to determine the transfer of radiocesium in vegetable-producing fields.

\subsection{Materials and Methods}

\subsubsection{Vegetable and Soil Samples}

Samples were obtained from two different locations. One was the agricultural research field at the Institute for Sustainable Agro-ecosystem Services located in Nishitokyo City, Tokyo (altitude approximately $60 \mathrm{~m}$ above sea level; this site is referred to as "Nishitokyo City"). This site was about $230 \mathrm{~km}$ away from the Fukushima Daiichi nuclear power plant. Potatoes (Irish Cobbler) and cabbage (YR Rakuzan) that grew in this field and the soil around these vegetable-producing fields were collected on 16 May 2011 (40 days after the settled cabbage planting and 47 days after potato planting), on 27 May 2011 (51 days after the settled cabbage planting and 58 days after potato planting) and on 20 June 2011 (75 days after the settled cabbage planting and 82 days after potato planting). Soil samples, mostly consisting of surface soil (depths of 0-5 cm), were sampled at the time of vegetable sampling. In addition, on 11 June 2011, more soil samples were collected at 5-cm intervals and at depths as great as $35 \mathrm{~cm}$ below the ground surface.

Potato (Kita-Akari), cabbage (Shikidori) and lettuce (Berkley) samples were collected from a mountain village (altitude approximately $420 \mathrm{~m}$ above sea level) located in the southeastern part of Fukushima Prefecture and about $60 \mathrm{~km}$ away from the Fukushima Daiichi nuclear power plant. They were sampled on 18 July 2011, 99 days after potato planting, 78 days after the settled cabbage planting and 49 days after the lettuce planting. Soil was sampled from each field at 5- or $10-\mathrm{cm}$ intervals and at depths as low as $30 \mathrm{~cm}$ below the ground surface. 


\subsubsection{Radioactive Nuclide Concentration Measurements}

We measured the concentrations of ${ }^{134} \mathrm{Cs}$ and ${ }^{137} \mathrm{Cs}$, both of which have a long half-life, as well as naturally occurring ${ }^{40} \mathrm{~K}$ using a germanium semiconductor detector (ORTEC, SEIKO EG\&G Co. Ltd.). For the samples collected on 16 May 2011, the measurement time was set to 50,000 s for the vegetable samples and 18,000 s for the soil samples. For all other samples, the measurement time was set to 3,600 s.

\subsection{Results and Discussion}

\subsubsection{Concentrations of Radioactive Nuclides in Vegetables and Soil (Tokyo)}

Table 7.1 shows the measured concentrations of the radioactive nuclides ${ }^{134} \mathrm{Cs},{ }^{137} \mathrm{Cs}$ and ${ }^{40} \mathrm{~K}$ in samples of potato leaves (both washed and unwashed), roots, tubers and soil. Among the potato samples collected 47 days after planting, an extremely small amount of radiocesium was detected in the washed $\left({ }^{137} \mathrm{Cs}\right.$ was detected but ${ }^{134} \mathrm{Cs}$ was not $)$ and unwashed (both ${ }^{134} \mathrm{Cs}$ and ${ }^{137} \mathrm{Cs}$ were detected) leaf samples. However, radiocesium $\left({ }^{134} \mathrm{Cs}\right.$ and $\left.{ }^{137} \mathrm{Cs}\right)$ was not detected in the unwashed leaf sample of potatoes collected 58 days after planting, although a very small amount was detected in the washed sample.

These results contradicted our predictions. This could have been because the detection limit for the unwashed leaf sample was about twice as high as that for the washed leaf sample, as indicated in Table 7.1. Because the amount of the unwashed leaf sample was less than that of the washed leaf sample, we suspected a greater detection limit for the unwashed leaf sample.

No radiocesium was detected in the root samples. With regard to tubers, which are the edible parts of plants, ${ }^{137} \mathrm{Cs}$ was detected at a concentration of $2.4 \mathrm{~Bq} / \mathrm{kg}$ wet weight in the sample collected 58 days after planting. Although the concentration of ${ }^{134} \mathrm{Cs}$ was lower than the detection limit, the measurement is provided as a reference only. ${ }^{134} \mathrm{Cs}$ and ${ }^{137} \mathrm{Cs}$ were not detected in the sample collected 82 days after planting.

To explain these results for tubers, we considered potassium (K) to be an important factor for tuber growth. Translocation and storage of carbohydrates occurs in staple crops rich in starch, such as potatoes, and potassium ions $\left(\mathrm{K}^{+}\right)$move around in these plants. A report on daikon radish described that cesium behaved like potassium in plants, in that the potassium concentrations in root tubers decreased after a certain stage of plant growth and cesium exhibited the same tendency (Ban-nai and Muramatsu 2002).

Comparison of the concentrations of ${ }^{40} \mathrm{~K}$ based on this hypothesis showed that the concentrations in the samples collected 82 days after planting were about $45 \%$ of those in the samples collected 58 days after planting. We estimated that the normal ${ }^{40} \mathrm{~K}$ concentration in potato tubers was $124.6 \mathrm{~Bq} / \mathrm{kg}$ wet weight. This was based on the assumption that the potassium concentration in potato tubers is $410 \mathrm{mg} / 100 \mathrm{~g}$ 


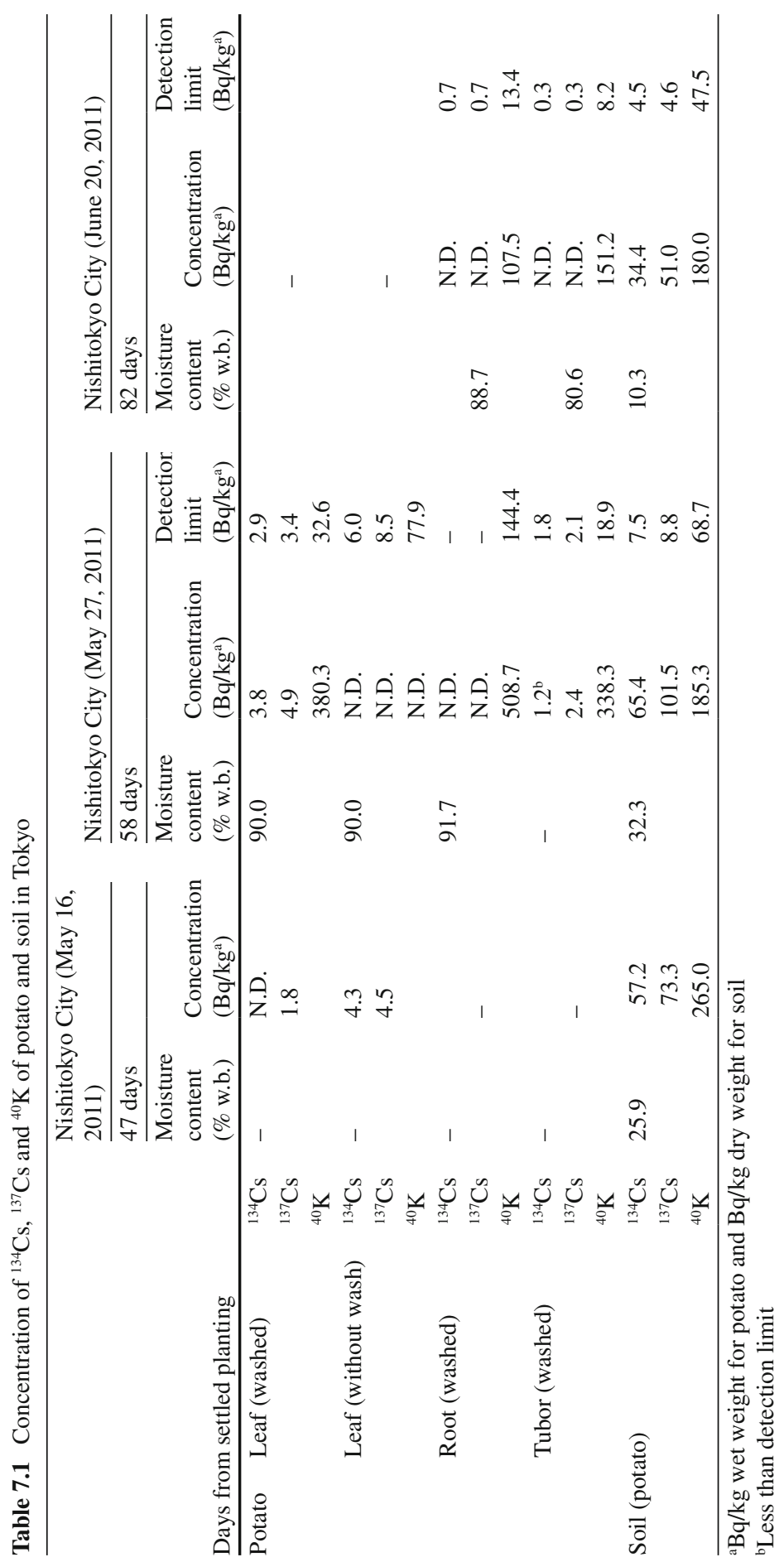


(Standard Tables of Food Composition in Japan, http://www.mext.go.jp/b_menu/ shingi/gijyutu/gijyutu3/toushin/05031802.htm) and the radioactivity of $1 \mathrm{~g}$ of potassium is $30.4 \mathrm{~Bq} / \mathrm{g}$, also considering the natural abundance of ${ }^{40} \mathrm{~K}$.

The value of $124.6 \mathrm{~Bq} / \mathrm{kg}$ wet weight was almost $82 \%$ of the value of $151.2 \mathrm{~Bq} / \mathrm{kg}$ wet weight measured in the sample collected 82 days after planting. This indicated that the measured concentration of ${ }^{40} \mathrm{~K}$ corresponded closely to the potassium concentration in tubers. Because the potassium concentration would naturally decrease to about $45 \%$ in the plants collected 58 days after planting, as with ${ }^{40} \mathrm{~K}$, we considered that the concentration of radiocesium, which behaves like potassium, would be reduced by half in the sample collected 82 days after planting and thus become undetectable.

Table 7.2 shows the concentrations of the radioactive nuclides ${ }^{134} \mathrm{Cs},{ }^{137} \mathrm{Cs}$ and ${ }^{40} \mathrm{~K}$ in the samples of cabbage leaves (edible parts and outer leaf, washed and unwashed), roots and soil. Radiocesium was detected only in the samples of the outer leaf (non-edible parts) collected at 40 days and 75 days after settled planting. Because the concentrations were lower in the samples collected 75 days after planting than in the samples collected 40 days after planting, we assumed deposition of radioactive fallout.

It should be noted that the measurements obtained for the samples collected 75 days after planting indicated that the concentration of ${ }^{137} \mathrm{Cs}$ was lower than that of ${ }^{134} \mathrm{Cs}$, although the detection sensitivity should have been higher for ${ }^{137} \mathrm{Cs}$. One reason for these results was assumed to be the low concentrations in the samples that were close to the detection limit. However, this needs to be clarified. The major reason for radiocesium becoming undetectable in the outer leaf samples collected 51 days after planting was believed to be the six times higher detection limit for these samples than that for samples collected 75 days after planting.

Figure 7.1 shows the vertical distributions in the soil for radioactive ${ }^{134} \mathrm{Cs},{ }^{137} \mathrm{Cs}$ and ${ }^{40} \mathrm{~K}$. The "depth" axis in this figure shows negative values because depth was measured using the bottom of the ridge as the reference point (zero) when collecting soil samples from the potato field. In the soil samples from the potato and cabbage fields, distribution of radiocesium was observed in the plow layer, which was $15 \mathrm{~cm}$ below the ground surface. The concentrations were particularly high in the soil samples from the surface and ridges. Tables 7.1 and 7.2 show that the radiocesium concentration in the surface soil varied depending on the day of sampling. We assumed that this indicated a two-dimensional concentration distribution.

\subsubsection{Concentrations of Radioactive Nuclides in Vegetables and Soil (Fukushima Prefecture)}

Table 7.3 shows the concentrations of the radioactive nuclides in samples of potato tubers (washed) and aerial parts (leaf and stem, washed). Table 7.4 shows the concentrations in samples of edible cabbage parts (unwashed and washed), outer leaves (washed) and roots (washed). The concentrations in the samples of edible lettuce parts (unwashed and washed) and roots (washed) are shown in Table 7.5. Figure 7.2 shows the distributions of radioactive ${ }^{134} \mathrm{Cs}$ and ${ }^{137} \mathrm{Cs}$ concentrations in the soil samples collected at different depths in each field. 


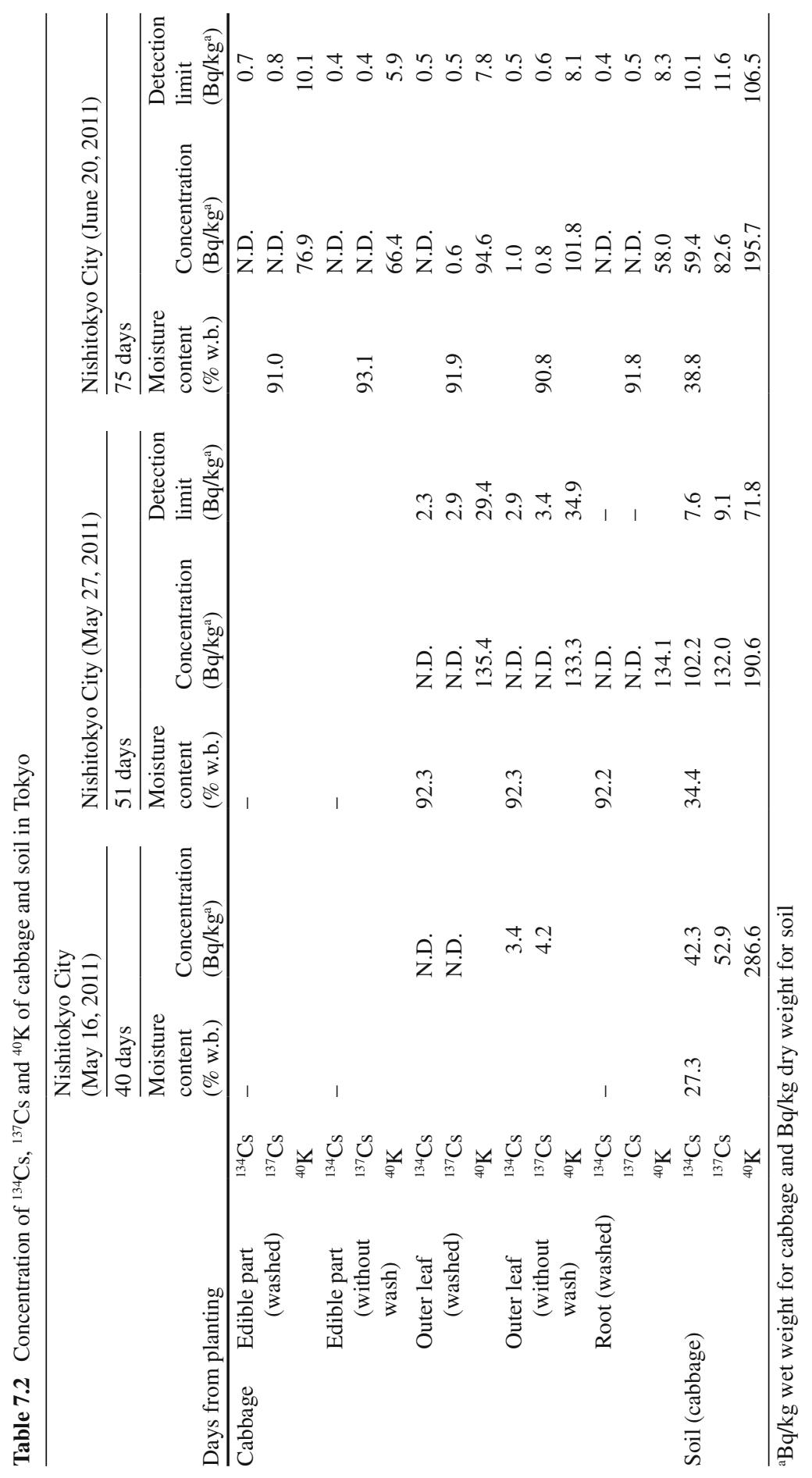


Fig. 7.1 Concentration of ${ }^{134} \mathrm{Cs}$ and ${ }^{137} \mathrm{Cs}$ at each depth in soil observed on 9 June 2011 at Institute for Sustainable Agro-ecosystem Services in Nishitokyo City

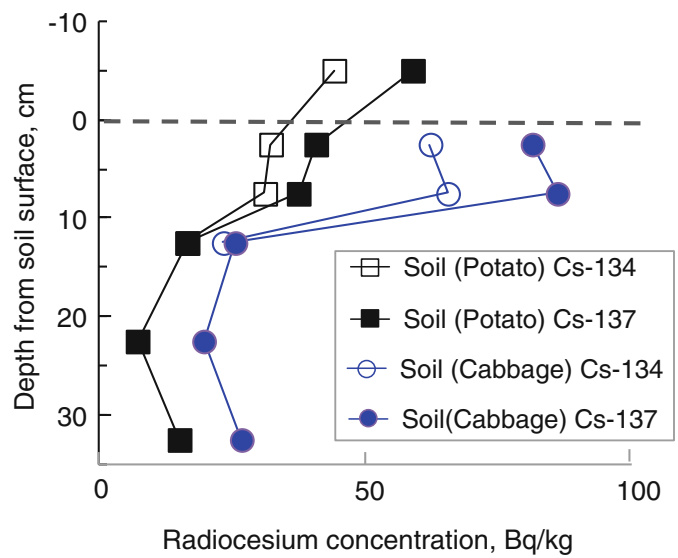

Table 7.3 Concentration of ${ }^{134} \mathrm{Cs},{ }^{137} \mathrm{Cs}$ and ${ }^{40} \mathrm{~K}$ of potato in Fukushima Prefecture (99 days after planting)

\begin{tabular}{|c|c|c|c|c|c|c|}
\hline \multirow[b]{2}{*}{ Nuclide } & \multicolumn{3}{|c|}{ Tuber, washed $\left(n=1^{b}\right)$} & \multicolumn{3}{|c|}{ Aerial part $($ leaf + stem $)$, washed $(n=1)$} \\
\hline & $\begin{array}{l}\text { Moisture } \\
\text { content } \\
\text { (\% w.b.) }\end{array}$ & Concentration $^{\mathrm{a}}$ & $\begin{array}{l}\text { Detection } \\
\text { limit }^{\mathrm{a}}\end{array}$ & $\begin{array}{l}\text { Moisture } \\
\text { content } \\
\text { (\% w.b.) }\end{array}$ & Concentration $^{\mathrm{a}}$ & $\begin{array}{l}\text { Detection } \\
\text { limit }^{\mathrm{a}}\end{array}$ \\
\hline${ }^{134} \mathrm{Cs}$ & 78.4 & 3.4 & 1.2 & 79.2 & 58.6 & 5.2 \\
\hline${ }^{137} \mathrm{Cs}$ & & 3.3 & 1.1 & & 52.7 & 5.0 \\
\hline${ }^{40} \mathrm{~K}$ & & 305.1 & 13.7 & & 581.0 & 47.5 \\
\hline
\end{tabular}

${ }^{\mathrm{a}} \mathrm{Bq} / \mathrm{kg}$ wet weight

${ }^{b} \mathrm{n}=1$ means the mean value of tubers with $2.8 \mathrm{~kg}$ wet weight

An extremely small amount of radiocesium $\left({ }^{134} \mathrm{Cs}\right.$ and $\left.{ }^{137} \mathrm{Cs}\right)$ was detected in the potato tuber sample (Table 7.3). In this case, ${ }^{134} \mathrm{Cs}$ and ${ }^{137} \mathrm{Cs}$ in the soil at depths from 0 to $5 \mathrm{~cm}$ were detected at 568.6 and $666.4 \mathrm{~Bq} / \mathrm{kg}$ dry weight (total of $1,235 \mathrm{~Bq} /$ $\mathrm{kg}$ dry weight), respectively (Fig. 7.2). With regard to the transfer of radiocesium, one study investigated the transfer rate from plant roots to organs in hydroponic conditions (Uchida et al. 1987).

They found that in root crops and leaf vegetables, the transfer rate of ${ }^{137} \mathrm{Cs}$, determined by (activity of plant sample/day)/(mean activity of culture solution), to roots is faster by about one order of magnitude than that to other plant organs located above the ground. In contrast, in root vegetables (daikon radish) growing in soil culture, the transfer factor for leaves is higher than that for tubers, with a ratio of 4.1 for ${ }^{137} \mathrm{Cs}$ (Ban-nai and Muramatsu 2002). Regardless of which hypothesis is adopted, the concentration of radiocesium in the aerial parts shown in Table 7.3 was thought to be too high to have resulted from uptake through root absorption. Thus, the high concentration was assumed to be due to the deposition of radioactive fallout.

The transfer factor from soil to potato tubers was calculated for reference. Based on the concentrations of ${ }^{137} \mathrm{Cs}$ in the tuber and soil samples $(583 \mathrm{~Bq} / \mathrm{kg}$ dry weight as a mean value for vertical positions from -10 to $10 \mathrm{~cm}$; not shown in Fig. 7.2), the transfer 


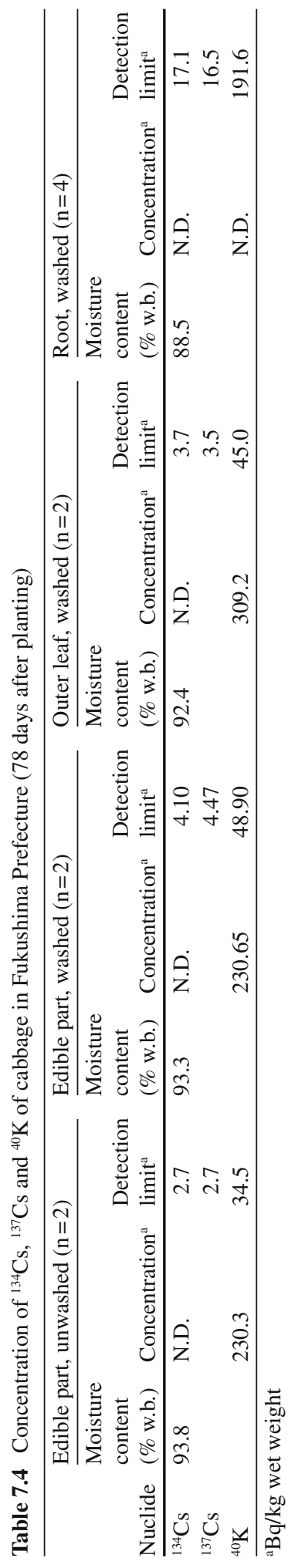




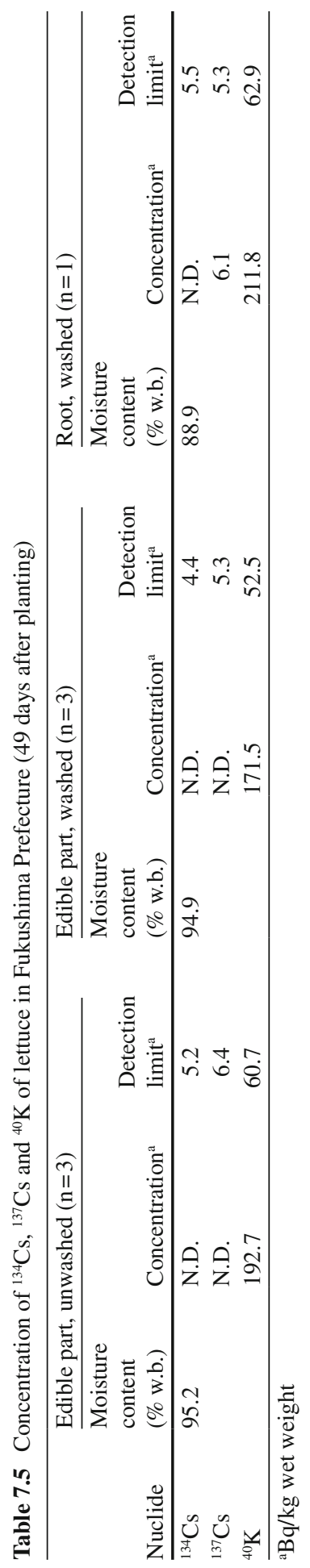


Fig. 7.2 Concentration of radiocesium $\left({ }^{134} \mathrm{Cs}+{ }^{137} \mathrm{Cs}\right)$ at each depth in soil observed on 18 July 2011 in Fukushima Prefecture

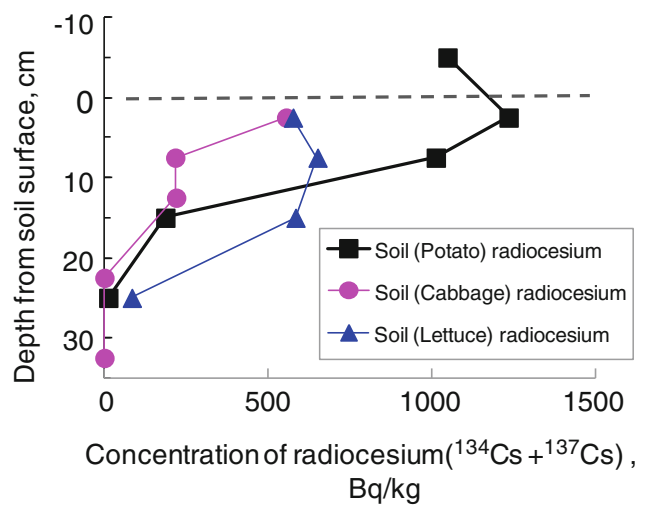

factor was estimated to be 0.0057 using the following equation: $\left({ }^{137} \mathrm{Cs}\right.$ concentration in tuber; fresh vegetable)/( ${ }^{137} \mathrm{Cs}$ concentration in soil; dry soil). This value was smaller than the index value of 0.067 (http://www.maff.go.jp/j/press/syouan/nouan/110527.html) provided by the Japanese Ministry of Agriculture, Forestry and Fisheries (MAFF), which was derived by the same equation. When the sum of the ${ }^{134} \mathrm{Cs}$ and ${ }^{137} \mathrm{Cs}$ concentrations was used in this calculation, the transfer coefficient was 0.0061 .

In cabbage, no radiocesium was detected in samples of the outer leaf (washed) and root (washed). In lettuce, a very small amount of ${ }^{137} \mathrm{Cs}$ was detected in a root sample but not in any other plant organ sample. In these cases, the maximum concentrations of ${ }^{134} \mathrm{Cs}$ and ${ }^{137} \mathrm{Cs}$ in the soil were found at depths ranging from 0 to $5 \mathrm{~cm}$ of 291.8 and $359.4 \mathrm{~Bq} / \mathrm{kg}$ dry weight (total of $651.2 \mathrm{~Bq} / \mathrm{kg}$ dry weight), respectively (Fig. 7.2). Data provided by MAFF in 2011 yielded the transfer factor of radiocesium from soil to vegetables in which the concentrations in soil were close to the values observed in Fukushima in our investigation (Ministry of Agriculture, Forestry and Fisheries, http://www.s.affrc.go.jp/docs/nogyo_gizyutu/pdf/3_1.pdf). Although we did not observe the transfer of radiocesium from the soil to cabbage or lettuce, it will be important to continue obtaining data on the transfer of radiocesium from soil with low contamination for further study.

The measured concentrations of radioactive nuclides in the soil showed a vertical distribution pattern within the plow layer for ${ }^{134} \mathrm{Cs}$ and ${ }^{137} \mathrm{Cs}$, with surface soil having a high concentration level (Fig. 7.2). These results corresponded with the results obtained in Nishitokyo City (Fig. 7.1).

\subsection{Conclusion}

We investigated the transfer of radiocesium from soil with low contamination to vegetables. An extremely small amount of ${ }^{137} \mathrm{Cs}$ was detected in the tuber samples of potatoes collected 58 days after they were planted in a dry field with a ${ }^{137} \mathrm{Cs}$ concentration of 50-100 Bq/kg dry weight. However, radiocesium was not detected in potato samples collected 82 days after planting. Potassium is known to be 
transported in plants to adjust the osmotic pressure in cells. We suspected that cesium behaved in much the same way as potassium, which resulted in a lower concentration in potatoes at harvesting season.

In potatoes grown in a dry field with a ${ }^{137} \mathrm{Cs}$ concentration of $530-670 \mathrm{~Bq} / \mathrm{kg}$ dry weight, a very small amount of ${ }^{137} \mathrm{Cs}$ was transferred to the tubers. This transfer coefficient was calculated to be 0.0057 , although this should be considered as a reference value only. This value is smaller than the index value provided by the Japanese MAFF. However, it should be noted that this index value was determined from data in the range of $0.00047-0.13$. In this investigation, any detectable transfer of cesium from the soil to the edible parts of cabbage or lettuce was observed. Because the transfer factor varies depending on soil characteristics, it will be necessary to collect more data for soil with a low contamination level and conduct more studies on the transfer of radiocesium from soil to vegetables in the fields where agricultural production is continuing.

Our investigation of soil did indicate a vertical distribution pattern for radiocesium concentrations, with a higher concentration in surface soil. We anticipate that by making the concentrations of radiocesium more uniform (reduced) by land cultivation, deep plowing or other soil mixing methods, the transfer of radiocesium will be reduced.

Acknowledgements This article is based on the collaborative research with Dr. Eriko Yasunaga, Dr. Daisuke Takada, Dr. Keitaro Tanoi, Mr. Hiroaki Shirai, Dr. Haruto Sasaki, Dr. Tomoko Nakanishi, Dr. Yoshio Makino (the University of Tokyo) and Dr. Yoshinori Kawagoe (Nihon University) with the assistance of Mr. Hirohumi Kubota, Mr. Kenichiro Ichikawa, Mr. Keisuke Yatsuda (the University of Tokyo), and Mr. Toru Haga and Mr. Shogo Suzuki (Samegawa village office, Higashi-Shirakawa-gun, Fukushima Prefecture).

Open Access This article is distributed under the terms of the Creative Commons Attribution Noncommercial License which permits any noncommercial use, distribution, and reproduction in any medium, provided the original author(s) and source are credited.

\section{References}

Ban-nai T, Muramatsu Y (2002) Transfer factors of radioactive Cs, Sr, Mn, Co and Zn from Japanese soils to root and leaf of radish. J Environ Radioact 63:251-264

Ban-nai T et al. (1994) Cultivation experiments on uptake of radionuclieds by mushrooms. Radioisotopes 43:77-82 (in Japanese)

Ban-nai T et al. (1995) Transfer factors of some selected radionuclides (radioactive Cs, Sr, Mn, Co and $\mathrm{Zn}$ ) from soil to leaf vegetables. J Radiat Res 36:143-154

Broadley MR, Willey NJ (1997) Environ Pollut 97(1-2):11-15

Ministry of Agriculture, Forestry and Fisheries. http://www.maff.go.jp/j/press/syouan/nouan/110527. html. Accessed 18 Aug 2012

Ministry of Agriculture, Forestry and Fisheries. http://www.s.affrc.go.jp/docs/nogyo_gizyutu/ pdf/3_1.pdf. Accessed 18 Aug 2012

Oshita $\mathrm{S}$ et al. (2011) Radioactivity measurement of soil and vegetables contaminated from low level radioactive fall out arised from Fukushima Daiichi nuclear accident—a study on institute of sustainable Agro-Ecosystem Services, Graduate School of Agricultural and Life Sciences, The University of Tokyo. Radioisotopes 60:329-333 (in Japanese) 
Oshita S et al. (2013) Radioactivity measurement of soil and vegetables due to Fukushima Daiichi nuclear power plant accident - case studies of low level contamination in Tokyo and Fukushima. Radioisotopes 62: 149-157 (in Japanese)

Schwaiger $M$ et al. (2004) Investigation of food contamination since the Chernobyl fallout in Austria. Appl Radiat Isot 61:357-360

Standard Tables of Food Composition in Japan (Fifth Revised and Enlarged Edition, 2005) Ministry of Education, Culture, Sports, Science \& Technology in Japan. http://www.mext. go.jp/b_menu/shingi/gijyutu/gijyutu3/toushin/05031802.htm. Accessed 18 Aug 2012

Tensho K et al. (1959) The uptake of ${ }^{134} \mathrm{Cs}$ and $\mathrm{K}$ by lowland and upland rice from soil, and their distribution in the plants. Soil Sci Plant Nutr 30(6):253-358 (in Japanese: title is tentatively translated by author)

Tsumura A et al. (1984) Behavior of radioactive Sr and Cs in soils and soil-plant systems. Bull Natl Inst Agric Sci Ser B 36:57-113 (in Japanese)

Uchida S et al. (1987) Transfer of radionuclides to crop plants through roots-radiocesium and strontium. Radioisotopes 36:575-580 (in Japanese)

Yonezawa S, Mitsui S (1965) Depressing effect of fertilizers and soil conditioners on strontium-90 and ceasium-137 uptake by rice plant. Soil Sci Plant Nutr 36(5):135-139 (in Japanese: title is tentatively translated by author)

Zehnder HJ et al. (1995) Uptake and transport of radioactive cesium and strontium into grapevines after leaf contamination. Radiat Phys Chem 46(1):61-69 